\title{
The impact of Functional Resistance Training on the effectiveness of the offensive and defensive performance for boxers
}

* Dr / Mostafa Mohammed Ahmed Nasr

\section{Introduction:}

Boxing one of the most sports which affected by the development in sports and coaching scinces. The physically, mentally, skillful, and psychological prepration which take the boxer to high performance. Tiana, W., et, al (2010) As functional resistance training becomes a more popular method to improve muscular fitness, and has been considered to be a better alternative than traditional resistance training for improving various measures of muscular fitness including strength, endurance, coordination and balance.

And Functional resistance training defines as a mix of all two types of training; Training for strength and balance at the same time. It is also an integrated and multi-level drills (Horizontal, sagittal, vertical)

Balance is one of the motor elements that must be considered when training motor skills. It is considered one of the basic components of motor skill. It is impossible to perform a sporting skill well if it is not linked to balance.

Balance is the ability to retain the center of mass when moving from one point to another.

Balance is the result of several body systems working together which is located primarily in the inner ear. Degeneration or loss of function in any of these systems can lead to balance deficits; it is responsible for the motor balance. The length of time that the episode of loss of balance lasts demonstrates device efficiency and individual's balance level.

Vom, H., (1995) It is suitable for all individuals at different levels of training and aims to improve the relationship between the

Assistant Professor of Athletic Training, Faculty of Physical Education - Mansoura University. Department of Physical Education and Movement Sciences - College of Education - Qassim University 
muscles and the nervous system.

Tiana et al. (2010) explained that through traditional programs muscle strength is increased for a muscle group without training on similar movements for a technical sports skill performance, while functional exercises include many of the joints and muscle activity of the upper and lower body part during each movement in training. They are also used as alternative options within the training methods to help improve the technical performance of juniors compared to traditional exercises as they are suitable for all ages, as well as contribute to the improvement of all physical abilities of the athletes, where they increase and enhance the endurance of the muscle and kinetic balance and fitness during the application of training programs where they lead to the muscles and multiple joints for the body and during the full scope of the motor joints.

Michael, B., (2004) believes that functional training programs consist of:

1. Core stability, few movements performed repeatedly with medium severity and with gradual progress in performance and aims to achieve stability and neuromuscular control.

2. Core Strength, dynamic movements using external resistors in all kinetic levels of and aims to achieve muscle strength and kinetic integration.

3. Core Power which is about movements that is characterized by the production of distinctive fast force

Wallace, BJ., Et, al (2006) explains that the resistance exercises using the rubber band are particularly important in many of strength training programs because of their effective impact on the technical performance and possible performance and integrated in the exercises along the extent of movement in order to reform and improve many of the sports movements. As the nature of performance on the ring needs fast feet movements with the sudden change of direction so that the boxer can dodge punches from the opponent or to reach the position at the perfect time to be able to make powerful punches; therefore the implementation of offensive or 
defensive or counter-offensive movements require the boxer to transmit the movement rapidly from the rear foot to the front in quick and short steps (case of attack), or to transmit the movement rapidly from the front foot to the rear in quick and short steps (case of counter attack), as well as during the move to the sides through pushing the grounds with one foot or both feet together while not lifting the weight of the body high, so that the movement would be in the form of fast, short and stable jumps.

It is clear that there is an agreement on a number of components such as power and speed (strength characterized by the speed), muscular strength and Agility, and these components are not separate from each other they are related and interrelated consisting sensory and physical field. The boxer on the ring needs strength characterized by the speed in the production of kinetic speed for the arms and legs in order to help him in punching or moving away from the opponent's defense or the implementation of the counterattack.
Repeating

these positions or moves during the rounds needs Agility in order to quickly change direction, and amount of endurance for the implementation of the two legs skills throughout the game. So the boxer needs to move his body very quickly to move away from the competitor's punches or (approaching) it in the proper time to punch or a set of punches. This requires the boxer to work on the development of muscular ability of the legs and Agility through workouts regarding such as muscular action during the performance on the ring.

This is consistent with what Abdul Fattah Khedr (1996), Mahmoud Khalifa (2002), Sami Hafez (2006) mentioned about the importance of foot work of a boxer, as it is one of the fundamental skills that the boxer should be fluent in implementation during the match rounds; whether to move in all directions (forward or backward or to the right- left side) or the transfer of one of the feet and build on the other foot (rotational movements).

As a result of the changing and successive positions facing the boxer on the ring, it

\section{Assiut Journal For Sport Science Arts}


requires him to master all kinds of odd and even moves easily and balance to be able to perform punching skills efficiently while saving efforts and being able to estimate various distances in accordance with the positions of the boxer on the ring and the preservation of balance during the movement of the feet, as well as distracting the opponent through changing speed direction.

Through theoretical researches, field studies, and surveys for many of the specialized studies, and the researcher's experience in the field of boxing training, and follow-up for most games local and international championships; it became clear that there are shortcomings in the performance of some movements of the legs, trunk and arms movements during the offensive and defensive performance during the rounds of match represented in the inability of the Boxer to take the right place at the right time to be able to punch or avoid punches from rival. Also some offensive and defensive performance that is done as fast as possible in the appropriate time, which adversely affects the level of performance and the outcome of the match.

Research Objective: The research aims to identify the impact of Functional Resistance Training exercises using Rubber band on the offensive and defensive performance of some thirdyear students at the Faculty of Physical Education - Mansoura University. They are specialized in boxing training.

Research Hypothese: The study hypothesis is that the Functional Resistance Training exercises using Rubber band positively affect the offensive and defensive performance of the study sample.

\section{Research procedures:}

- Methodology: the experimental method using the experimental group and preand post measurement.

- Place: the boxing Hall of the Faculty of Physical Education, Mansoura University.

- Time: pre- and post measurements were conducted. Functional Resistance Training exercises during the special preparation period in the training program for boxers is applied in the period from 03/06/2015 till 08/14/2015. 
- Research sample: The research sample was chosen intentionally from young boxers who play in Mansoura stadium. The number is (5) boxers.

Measurements and tests:

- Basic measurements: (age -overall length - weight training age)

- Muscular ability for both legs: the Standing broad jump test $(\mathrm{cm})$

- Distinctive strength for two arms: throw the medical ball $3(\mathrm{~kg})$ for the farthest distance with the left and right hand $(\mathrm{cm})$

- Measurement of defensive movements of both legs:

- Side-stepping from a steady position 10 seconds (number) - Stepping forward

\section{Equipment \& Instruments:}

- Restameter to measure the length

- a tape measure

- Stopwatch (.01 of a second)

- Punching Bags

- Rubber bands and back from a steady position 10 seconds (number)

- $\quad$ Agility Test: moving back and front between the flags and punching straight with right and left hand towards the head (sec).

- Measuring the kinetic balance: Testing the time of lost balance with the Astralis device (w).

- Test the offensive performance: the effectiveness of the offensive performance coefficient.

- Test the defensive performance: the effectiveness of the defensive performance coefficient.

Pre- measurements: conducted on 3-4 / 6/2015 and then variables have been confirmed for sample before the start of the experiment as shown in table (1)

Table (1)

statistic description of the study sample (N=5)

Assiut Journal For Sport Science Arts 


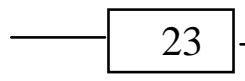

\begin{tabular}{|c|c|c|c|c|c|c|}
\hline $\mathbf{S}$ & Variable & $\begin{array}{l}\text { Unit of } \\
\text { Measurem } \\
\text { ent }\end{array}$ & $\begin{array}{l}\text { Averag } \\
\mathrm{e}\end{array}$ & $\begin{array}{c}\text { Mea } \\
\mathrm{n}\end{array}$ & $\begin{array}{l}\text { Deviati } \\
\text { on }\end{array}$ & $\begin{array}{l}\text { Skewne } \\
\text { ss }\end{array}$ \\
\hline 1 & Age & Year & 20.42 & 20 & 0.427 & 0.562 \\
\hline r & Length & $\mathrm{Cm}$ & 177.2 & 178 & 2.167 & $1.107-$ \\
\hline r & Weight & $\mathrm{Kg}$ & 74.4 & 75.00 & 3.346 & $0.179-$ \\
\hline$\varepsilon$ & Training Age & Year & 3.54 & 3.5 & 0.456 & 0.263 \\
\hline 。 & Standing broad jump test & $\mathrm{Cm}$ & 205.6 & 205 & 3.781 & 0.476 \\
\hline 7 & $\begin{array}{l}\text { Throwing a Medical ball of } 3 \\
\mathrm{~kg} \text { for the farthest distance } \\
\text { with the right hand }\end{array}$ & $\mathrm{Cm}$ & 9.7 & 9 & 1.524 & 1.377 \\
\hline v & $\begin{array}{l}\text { Throwing a Medical ball of } 3 \\
\mathrm{~kg} \text { for the farthest distance } \\
\text { with the left hand }\end{array}$ & $\mathrm{Cm}$ & 8.6 & 8.5 & 0.741 & 0.404 \\
\hline$\wedge$ & $\begin{array}{l}\text { move back and forth between } \\
\text { the flags and punching } \\
\text { straight with right and left } \\
\text { hand towards the head }\end{array}$ & $\mathrm{Sec}$ & 9.88 & 9.80 & 0.563 & 0426 \\
\hline 9 & $\begin{array}{l}\text { Side-stepping from a steady } \\
\text { position } 10 \text { seconds }\end{array}$ & Number & 22.3 & 22.5 & 0.274 & $2.190-$ \\
\hline 1. & $\begin{array}{l}\text { stepping forward and back } \\
\text { from a steady position } 10 \\
\text { seconds }\end{array}$ & Number & 23.5 & 23.00 & 1.323 & 1.134 \\
\hline 11 & Time of lost balance & $\mathrm{Sec}$ & 8.69 & 8.5 & 0.317 & 1.798 \\
\hline ir & $\begin{array}{l}\text { effectiveness of the offensive } \\
\text { performance }\end{array}$ & Degree & 0.216 & 0.22 & 0.011 & $1.052-$ \\
\hline ir & $\begin{array}{l}\text { effectiveness of the defensive } \\
\text { performance }\end{array}$ & Degree & 0.228 & 0.23 & 0.025 & 0.232 \\
\hline
\end{tabular}

Table (1) shows that the value of the Skewness coefficient for measurements of the research sample ranged between $(-2.190,1.377)$, and that these values are confined between $(-3,+3)$ which shows average values for sample research before the experiment. Functional Resistance Training exercises using Rubber band were on $6 / 6 / 2015$ to $12 / 8 / 2015$ during a preparation period of a training program for boxers for a period of (10) weeks - (3) training units per week with (2 hours) by (8-12) repetitions, and (3-5) sets.

Upper Limb Exercises:

- Chest Press \& Single Leg Chest Press (stand. Open legs. Lean Body Forward. Arms Forward. Two sides of Rubber band caught by hands. Hanged high from its middle) bend elbows with the exchange of the two legs lifted and bended back.

- Chest Fly (stand. Bend Knee of front leg. Lean Body 
Forward. Arms Forward. Two sides of Rubber band caught by hands. Hanged high from its middle. Move arms aside.

- Atomic Push Up (Horizontal abdominal . Back facing Rubber band. Resting on the feet on both sides of the rubber band. Hanging high from the middle), bend your knees and moving the feet in front of the knees to touch the chest and then extend the knees fully bent with elbows.

- Back Row (Low, 45 deg., \& High) (stand. Face rubber band. Bend. Two sides of Rubber band caught by hands Hanging high from the middle). Tightening the rubber band with hands while leaning back, then raise the upper hand aside towards the 45-degree bottom and move hands out then raise the upper hand aside. - "W" Deltoid Fly \& "T" Deltoid Fly (stand Face rubber band. bend back leg knee. Arms forward. the Rubber band Caught hanging from the high middle by hands. Hanging from the high middle) move the arms aside with D knee background men and raising the trunk high and then put the upper arm tilted aside the drape down and elbows.

- Triceps Press (stand. Bend the foreleg knee. fore mile body. Arms forward. Rubber band caught by hands from the two sides. Hanging from the high middle to the back) raise the upper hands high and bend elbows.

- High Biceps Curl (stand. Face rubber band. Arms forward. Body leaned back. Keeping the Rubber band Caught hanging from the high middle by hands) bend elbows fully to flatten the rubber band.

Lower Limb Exercises:

- Single Leg Balance Squat (sitting half-squatting. A leg forward. Facing Rubber band. arms forward high. Rubber band Caught hanging from the high middle by hands). Extend the knee fully with lowering the arms tilted forward down.

- Suspended Lunge (stand in the middle. A Leg backward. The Back facing Rubber band. Foot resting on both ends hanging from the middle high) bend knee $o$ the foreleg with lifting of the rear leg thigh tilted backward and put the arms on the chest.

- (Hips lifted) Hamstring Curl (bench pressing. The two legs tilted forward high. Rubber band Facing Arms out. Feet Resting on both sides of Rubber band hanging from a high middle) fully bend your knees and move the feet back to flatten the Rubber band.

- Hip Press (bench pressing. Thighs high. Bend knees. Facing Rubber band hanging from the middle high. Arms out. Resting on the feet on both sides of the Rubber band) lifting the pelvic up.

Exercises for the core muscles 
- High Back Extension (stand. Facing Rubber band hanging from the high middle Arms high. Holding rubber band with hands) trunk high with moving arms high aside.

- High Torso Rotation (stand. Open legs. Facing Rubber band hanging from the high middle. Arms forward inside. Holding rubber band with hands) exchange wrap the trunk aside.

- Kneeling Rollout (Kneeling. Facing Rubber band hanging from the high middle. Arms forward down. Holding rubber band with hands) bend trunk with thighs forward and raise arms tilted high forward.

- Leg Raise (bench pressing .legs high angle of 90 degrees. Facing Rubber band hanging from the high middle. Arms forward down. Holding rubber band with hands) put the two legs forward down at an angle of 45 degree.

- Suspended Pike from Hands (Horizontal abdominal. Back facing Rubber band. feet Resting on the on both sides of rubber band. Hanging from the high middle) lifting the pelvic up with moving the feet to flatten the rubber band.

- Suspended Pendulum (Horizontal abdominal. Back facing Rubber band. feet Resting on the on both sides of rubber band. Hanging from the high middle) exchange twist moving the pelvic and legs.

- Suspended Side Plank with Reach Through (Horizontal sides abdominal. The side facing Rubber band hanging from the high middle. Arms Free aside. The high arm of the other arm is aside. Rest Elbow of the other arm on the ground. Resting the feet on both sides of rubber band) Body Wrap quarter roll with the status of free arm helped the other arm.

The following should be taken into account during the application of exercises:

- focus on strengthening the muscles of the upper and lower limb and firming core muscles.

- The application of stretch exercises at the end of the module to get the muscles to relax in order to return to a normal state.

- $\quad$ Training method used $\mathrm{s}$ high-intensity using circuit training system

- $\quad$ The circuit includes (5) trainings/ (8-12) repetitions / (3-5).sets

Control the intensity of training loads is through the change between performance time and resting between workouts and also between the groups.

- Post Measurements:
Post measurements were
conducted after the completion
of the training program on the
application of the research
sample in the period from $13-$
$14 / 8 / 2015$ according to the
pre-measurement.

The statistical processing

\section{Assiut Journal For Sport Science Arts}


(Arithmetic average - standard deviation - Mean - skewness coefficient - Wilcoxon test Enhancement Ratio)

Results \& Discussions:

Table (2)

the significance $o$ differences between pre and post measurements

for the experiment group of extensor and flexor muscles of elbows and shoulders $\quad \mathrm{N}=5$

\begin{tabular}{|c|c|c|c|c|c|c|c|c|}
\hline \multirow[b]{2}{*}{$S$} & \multirow[b]{2}{*}{ Variable } & \multirow{2}{*}{$\begin{array}{c}\text { Average } \\
\text { pre } \\
\text { measure }\end{array}$} & \multirow{2}{*}{$\begin{array}{c}\text { Average } \\
\text { Post } \\
\text { measure }\end{array}$} & \multicolumn{2}{|c|}{ Positive ranks } & \multicolumn{2}{|c|}{ Negative ranks } & \multirow[b]{2}{*}{$\begin{array}{c}(\mathrm{Z}) \\
\text { Value }\end{array}$} \\
\hline & & & & $\begin{array}{c}\text { Average } \\
\text { ranks }\end{array}$ & $\begin{array}{l}\text { Total } \\
\text { ranks }\end{array}$ & $\begin{array}{c}\text { Average } \\
\text { ranks }\end{array}$ & $\begin{array}{l}\text { Total } \\
\text { ranks }\end{array}$ & \\
\hline 1 & $\begin{array}{l}\text { Standing } \\
\text { broad } \\
\text { jump test }\end{array}$ & 205.6 & $Y 19.4$ & 3.00 & 15.00 & - & - & 2.041 \\
\hline 2 & $\begin{array}{l}\text { Throwing a } \\
\text { Medical ball } \\
\text { of } 3 \mathrm{~kg} \text { for } \\
\text { the farthest } \\
\text { distance with } \\
\text { the right } \\
\text { hand }\end{array}$ & 9.7 & 12.8 & 3.00 & 15.00 & - & - & 2.060 \\
\hline 3 & $\begin{array}{l}\text { Throwing a } \\
\text { Medical ball } \\
\text { of } 3 \mathrm{~kg} \text { for } \\
\text { the farthest } \\
\text { distance with } \\
\text { the left hand }\end{array}$ & 8.6 & 11.00 & 3.00 & 15.00 & - & - & 2.041 \\
\hline 4 & $\begin{array}{l}\text { move back } \\
\text { and forth } \\
\text { between the } \\
\text { flags and } \\
\text { punching } \\
\text { straight with } \\
\text { right and left } \\
\text { hand } \\
\text { towards the } \\
\text { head }\end{array}$ & 9.88 & 7.68 & - & - & 3.00 & 15.00 & 2.060 \\
\hline 5 & $\begin{array}{l}\text { Side- } \\
\text { stepping } \\
\text { from a } \\
\text { steady } \\
\text { position } 10 \\
\text { seconds }\end{array}$ & 22.3 & 26.7 & 3.00 & 15.00 & - & - & 2.032 \\
\hline
\end{tabular}

Follow Table (2)

the significance $o$ differences between pre and post measurements for the experiment group of extensor and flexor muscles of elbows and shoulders $\quad \mathrm{N}=5$ 


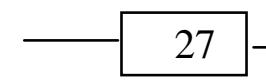

\begin{tabular}{c|c|c|c|c|c|c|c|c}
\hline \hline $\mathrm{S}$ & Variable & $\begin{array}{c}\text { Average } \\
\text { pre } \\
\text { measure }\end{array}$ & $\begin{array}{c}\text { Average } \\
\text { Post } \\
\text { measure }\end{array}$ & $\begin{array}{c}\text { Pvositive ranks } \\
\text { ranks }\end{array}$ & $\begin{array}{c}\text { Total } \\
\text { ranks }\end{array}$ & $\begin{array}{c}\text { Averative ranks } \\
\text { ranks }\end{array}$ & $\begin{array}{c}\text { Total } \\
\text { ranks }\end{array}$ & Value \\
\hline \hline 6 & $\begin{array}{l}\text { stepping } \\
\text { forward and } \\
\text { back from a } \\
\text { steady } \\
\text { position } 10 \\
\text { seconds }\end{array}$ & 23.3 & 27.6 & 3.00 & 15.00 & - & - & 2.121 \\
\hline 7 & $\begin{array}{l}\text { Time of lost } \\
\text { balance }\end{array}$ & 8.69 & 5.14 & - & - & 3.00 & 15.00 & 2.032 \\
\hline 8 & $\begin{array}{l}\text { effectiveness } \\
\text { of the } \\
\text { offensive } \\
\text { performance }\end{array}$ & 0.216 & 0.294 & 3.00 & 15.00 & - & - & 2.032 \\
\hline & $\begin{array}{l}\text { effectiveness } \\
\text { of the } \\
\text { defensive } \\
\text { performance }\end{array}$ & 0.228 & 0.286 & 3.00 & 15.00 & - & - & 2.032 \\
\hline \hline
\end{tabular}

* (Z) Value at the 0.05 level $=1.96$

Table (2) shows that there is no statistically significant differences between the mean pre measurements of the study sample for the post measurement at the level $(0.05)$

in all the physical variables and the coefficient of the offensive and the defensive performance for the post measurement. This is confirmed by the $\mathrm{Z}$ value.

Table (3)

Enhancement Value of extensor and flexor muscles of elbows and shoulders

\begin{tabular}{c|l|c|c|c|c}
\hline \hline S & \multicolumn{1}{|c|}{ Test Name } & $\begin{array}{c}\text { Pre } \\
\text { measurement }\end{array}$ & $\begin{array}{c}\text { Post } \\
\text { measurement }\end{array}$ & $\begin{array}{c}\text { Mean } \\
\text { Differ. }\end{array}$ & $\begin{array}{c}\text { Enhancement } \\
\%\end{array}$ \\
\hline \hline$r$ & $\begin{array}{l}\text { Standing broad } \\
\text { jump test }\end{array}$ & 205.6 & 219.2 & 13.6 & 7. \\
\hline $\begin{array}{l}\text { Throwing a Medical ball } \\
\text { of 3 kg for the farthest } \\
\text { distance with the right } \\
\text { hand }\end{array}$ & 9.7 & 12.8 & 3.1 & 32.00 \\
\hline $\begin{array}{l}\text { Throwing a Medical ball } \\
\text { of 3 kg for the farthest } \\
\text { distance with the left } \\
\text { hand }\end{array}$ & 8.6 & 11.00 & 2.4 & 27.9 \\
\hline \hline
\end{tabular}

Follow Table (3)

Enhancement Value of extensor and flexor muscles of elbows and shoulders

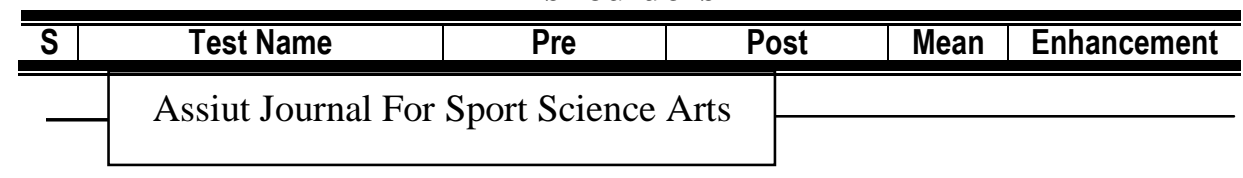




\begin{tabular}{|c|c|c|c|c|c|}
\hline & & measurement & measurement & Differ. & $\overline{\%}$ \\
\hline$\varepsilon$ & $\begin{array}{l}\text { move back and forth } \\
\text { between the flags and } \\
\text { punching straight with } \\
\text { right and left hand } \\
\text { towards the head }\end{array}$ & 9.88 & 7.68 & 2.2 & 22.3 \\
\hline 0 & $\begin{array}{l}\text { Side-stepping from a } \\
\text { steady position } 10 \\
\text { seconds }\end{array}$ & 22.3 & 26.7 & 4.4 & 19.7 \\
\hline 7 & $\begin{array}{l}\text { stepping forward and } \\
\text { back from a steady } \\
\text { position } 10 \text { seconds }\end{array}$ & 23.5 & 27.6 & 4.1 & 14.4 \\
\hline v & Time of lost balance & 8.69 & 5.14 & 3.55 & 40.9 \\
\hline$\wedge$ & $\begin{array}{l}\text { effectiveness of the } \\
\text { offensive performance }\end{array}$ & 0.216 & 0.294 & 0.078 & 36.1 \\
\hline 9 & $\begin{array}{l}\text { effectiveness of the } \\
\text { defensive performance }\end{array}$ & 0.228 & 0.286 & 0.058 & 25.4 \\
\hline
\end{tabular}

Table (3) shows that the highest percentage of enhancement was to the time of lost balance with an amount of $(6.6 \%)$. of $(40.9 \%)$, while the lowest rate of improvement was to the Standing broad jump test with an

amount

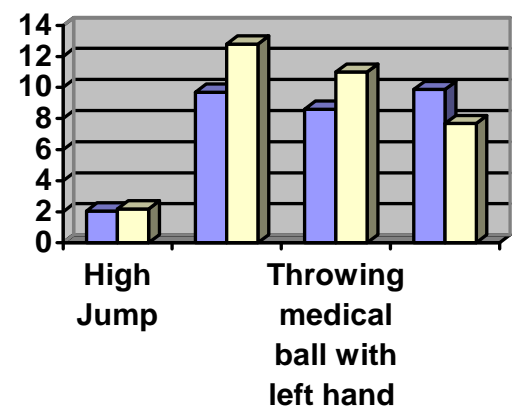

Diagram (1) the significance o differences between pre and post measurements for the muscular strength of legs and arms and Agility 


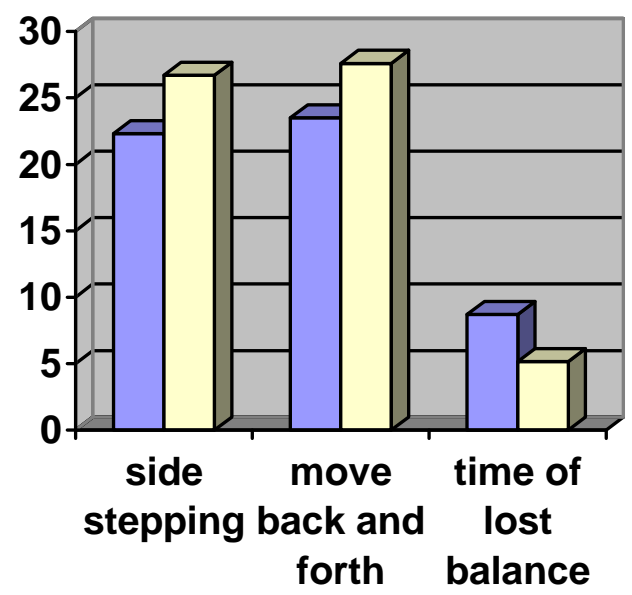

$\square$ Pre measurement $\square$ Post measurement

\section{Diagram (2) the significance of differences between pre and post} measurements for move side, back and front

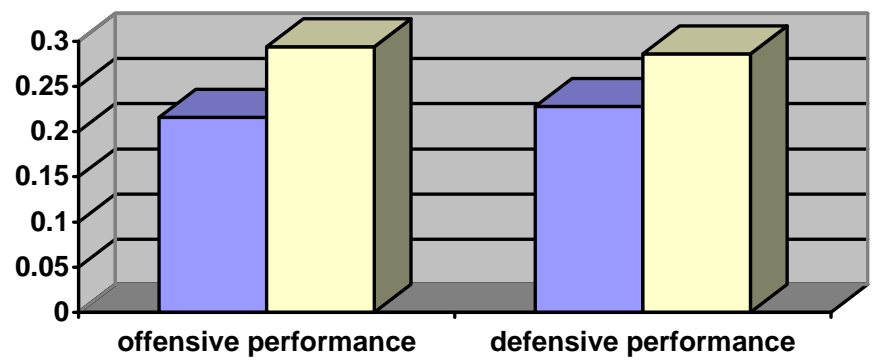

$\square$ pre measurement $\square$ post measurement

Diagram (3) the significance of differences between pre and post measurements for in the coefficient of the offensive and defensive Discussion

\section{performance}

It is evident from Table (2) and diagrams (1), (2) the presence of significant differences in favor of the post measurement at the level (0.05) in physical variables under study, a muscular strength for legs and strength characterized by the speed of the arms and the kinetic balance and Agility where the $(Z)$ value calculated higher than its Tabulated value $( \pm 1.96)$ at the 0.05 level of significance.The average Standing broad jump test (219.2) $\mathrm{cm}$ and the average of 
throwing $3 \mathrm{~kg}$ Medical ball with the right hand (12.8) $\mathrm{m}$ and throwing $3 \mathrm{~kg}$ Medical ball with the left hand (11.00) $\mathrm{m}$. the average move back and forth between flags with straight punching right and left towards the head (26.7) and the average forward and side stepping from standing by is 10 sec (26.7) and the average stepping front and back from standing by is $10 \mathrm{sec}$ (27.6) and the average time of lost balance is (5.14) Sec.The researcher found that this is due to the positive impact of Functional Resistance Training exercises using Rubber band, which were applied during the study sample physical setup in the period under study. This is consistent with what Tiana (2010) said; that Functional Resistance Training exercises are frequently used to improve the fitness of the muscles more than traditional exercises including strength, speed, balance and coordination exercises.

They are also used as alternative options within the training methods to help improve the technical performance of the juniors compared to traditional exercises as they are suitable for all ages, as well as contribute to the improvement of all physical abilities of the athletes, where they increase and enhance muscle strength, kinetic balance, and Agility during the application of training programs where they lead to multiple muscles and joints of the body and during the full range of joints movements.

This is confirmed by the enhancement percentage of Standing broad jump test which was $(6.6 \%)$. Throwing 3 $\mathrm{kg}$ Medical ball with the right hand was $32.00 \%$. throwing 3 $\mathrm{kg}$ Medical ball with the left hand was $27.9 \%$. moving back and forth between flags with straight punching right and left towards the head was $22.3 \%$. forward and side stepping from standing was $19.7 \%$. stepping front and back from standing is $14.4 \%$. the time of lost balance is $40.9 \%$.

This is also consistent with what Foam (1995) said; Functional Resistance Training exercises suit all individuals with different levels of training and aims to improve the relationship between the muscles and nervous system. In addition, Michel (2004) believe that Functional training 


\section{1}

programs lead to improved muscle strength and neuromuscular control and Kinetic integration and strength characterized by the speed.

The results of the study are consistent with the results of both Adams Et al (1992), and Conry1994 regarding the view that the functional exercises lead to increased muscular strength in both legs and some of the physical requirements such as (Speed and Agility) to the muscles of the legs in practiced sport activity.

Table (2) and Diagram (3) refer to the presence of significant differences at the 0.05 level for the benefit of post measurement in the coefficient of the effectiveness of the offensive and defensive performance under study which is due to the positive impact of Functional Resistance Training exercises using Rubber band, which was applied during your preparation period a study sample to improve the level of performance where the average performance of the offensive (0.294) degrees and the average performance of the defensive (0.286) degree. The percentage increase $(36.1 \%$,
$25.4 \%$ ) and this is due to the positive impact for Functional Resistance Training exercises using Rubber band that have been applied during your study sample preparation period to increase the strength of muscles of the upper and lower limb muscles and core muscles. This is in line with what was said by Wallacy et al. (2006) that the resistance exercises using Rubber band has a special stature in all strength training programs because of their effective impact on the performance of technical performance, it is possible to integrate them in the exercises along the extent of the sports movement in order to repair and improve many of the sports movements Bamjarzr \& Jackson (1999) and Carr (1994) believe that the balance is one of the kinetic elements that must be considered when training any kinetic skills, dynamic, and sport skill cannot performed properly if not linked to balance.

The results of the current study is consistent with the results of Applied games in the boxing; as the attack and the effective defense is strongly associated with a high level of 
development in all aspects and forms of resistance of the boxer during Applied punching the specific to improve the offensive and the defensive performance.

\section{Conclusions:}

Through the presentation and discussion of the results, the following conclusions could be reached:

- Functional Resistance Training exercises using Rubber band lead to improving muscular strength in both legs and strength characterized by the speed, kinetic balance and Agility for the study sample.

- Functional Resistance Training exercises using Rubber band lead to improving the level of effectiveness of the offensive performance in terms of $(36.1 \%)$ while the effectiveness of the defensive performance was $(25.4 \%)$ for the study sample.

\section{Recommendations:}

In the light of the outcome of the research findings, the researcher recommends the following:

- Applying Functional Resistance Training exercises using Rubber band in the training programs for boxers.

- Diversity of application of Functional Resistance
Training exercises using Rubber band to the muscles of the upper and lower limb and core muscles because of its positive impact on the effectiveness of the offensive and defensive performance of boxers.

- The need to make measurements of muscular strength to the muscles of the lower and upper limb and (core muscles), and the motor balance, and working to improve them during various training periods.

\section{References:}

\section{Abdel-Fattah}

Fathi

Khader 1996 : The Reference in boxing, Almaaref, Alexandria. P. 127

2. Adams. Et al( 1992 ) :The effect of six weeks of squat plyometric and squat plyometric training on power production , Journal of applied sport science research, U.S.A.pp (31- 47)

\section{Baumgarther,T.,}

Jackson, A.,

(1999) :

Measurement for Evaluation in physical Education and Drills Science,6th,ed,McGraw Hill,Boston, .pp231.

\section{Carr, C.,}

(1994):

Mechanics of Sport , Apractitioner's Guide, Human Kinetics, Champaign, .pp88. 
5. Conry, T. $R$ (1994):

Plyometric training and its effect on speed, strength and power of inter collagiatc athletes, microform Pub. U.S.A.pp(74- 91)

6. Davids $\mathbf{K}$, Button $\mathbf{C}$, Bennett S (2007): Dynamics of skill acquisition: aconstraints -Ied approach, illustrated edn:Human Kinetics. .pp

7. Davis,B.,Bull,Roscoe,J.,\& Roscos,D., (1997) : Physical Education and the Study of Sport,3rd,ed,Mosby, London, .pp116.

8. Doug,W. (1999) : Boxers start-up : Abeginners guide to boxing, Track Pub.San diego,Calfornia , U.S.A.pp 169 9. Fabio, C., (2004): function training for sports, Human Kinetics: Champaign IL, England,.pp27 .

10. Fiedler, -H. (1995): Observation of Technical Tactical Actions in Boxing Experiences, scualian-forma (Roma), APR / June, Italian,

\section{Ismail}

Mohamed

Hamid

Ghoneim, Diaa Eddin Azab, Atef Mgaroy (2002) : Boxing (education, training and management), Dar Al Sadaa, Cairo. p 169
12. Mahmoud Abdu Khalifa 2002 : The impact of the use of two teaching techniques of some basic skills and physical attributes for beginners in boxing, unpublished $\mathrm{PhD}$ thesis, Faculty of Physical Education in Port Said, Suez Canal University, P (20.28)

13. Michael Boyle (2004) : Functional Balance Training Using a Domed Device ,j Spine, 21, pp2640-2650 .

\section{Mohamed Talaat Ibrahim}

1984 : Proposed training program to improve the endurance of the balance keeping device for boxers, the Sport for All Conference, Faculty of Physical Education for Boys, Helwan University. $p$ 319.

\section{Mustafa Mohamed Nasr}

2002 : The impact of a proposed training program (physical - Skillful) on the development of some of the physical characteristics and effectiveness of skillful performance of the young boxers, unpublished Master Thesis, Faculty of Physical Education, Mansoura University. P (45.46) Tiana Weiss, Jerica Kreitinger, Hilary Wilde, Chris Wiora, Michelle Steege Lance Dalleck, Jeffrey Janot ., (2010) 
: Effect of Functional Resistance Training on Muscular Fitness Outcomes in Young Adults, J Exerc Sci Fit . Vol 8 . No 2 .pp 113-122 . 16. Sami Moheb Hafez (2006): An introduction to the modern boxing, 2nd version, Shagaret Al-Durr Library, Mansoura. $133 \mathrm{p}$

17. Tiana Weiss, Jerica Kreitinger, Hilary Wilde, Chris Wiora, Michelle Steege Lance Dalleck, Jeffrey Janot ., (2010) : Effect of Functional Resistance Training on Muscular Fitness Outcomes in Young Adults, J Exerc Sci Fit . Vol 8 . No 2 .pp 113-122.
18. Vom, H., A.(1995): The problem of skill specificity in complex athletic tasks: A revisitation. International Journal of Sport Psychology 26, pp249-261.

19. United states ametear boxing (1995) : Coaching olympic style boxing, Pub. I. L. Cooper Colorado Springs U.S.A..pp76

20. Wallace, BJ, Winchester, $\mathrm{JB}$, and McGuigan, MR. , (2006) : Effects of elastic bands on force and power characteristics during the back squat drills. Journal of Strength Condation Resistance, 20: pp 268-27 